\title{
Delayed Replantation of an avulsed permanent tooth in a young patient-Does Silver Diammine Fluoride surface treatment has a role?
}

\author{
Sonu Acharya ${ }^{1}$ \\ ${ }^{1}$ Siksha 'O' Anusandhan University
}

January 24, 2022

\begin{abstract}
Dental trauma in children are common occurences.Avulsion of anterior teeth due to trauma is seen in both primary and young permanent teeth. The standard protol for avulsion in permanent teeth is immediate replantation but many a times its not possible.Delayed replantation of avulsed permanent teeth has a poor prognosis.
\end{abstract}

Delayed Replantation of an avulsed permanent tooth in a young patient-Does Silver Diammine Fluoride surface treatment has a role?

Running Title-Role of SDF in avulsed permanent tooth

Abstract

Dental trauma in children are common occurences.Avulsion of anterior teeth due to trauma is seen in both primary and young permanent teeth. The standard protol for avulsion in permanent teeth is immediate replantation but many a times its not possible. Delayed replantation of avulsed permanent teeth has a poor prognosis still it is worth a try to replant an avulsed tooth for the completion of facial growth and to prevent the psychological impact the loss of anterior teeth can have on a young child.Here we discuss a case of replantation of Maxillary anterior teeth in a seven years old male child who reported sixteen hours after the trauma. This is probably the first case in literature where application of Silver Diammine Fluoride(SDF)on root surface to prevent resorption was done, which is the main reason of failure of teeth with delayed replantation.

Keywords-Avulsed teeth,Replantation,Silver Diammine Fluoride,Trauma

Introduction

Complete displacement of tooth from the socket is termed as avulsion. The prevalence of avulsed permanent teeth is $0.5 \%-18.3 \%{ }^{1}$ The prevalence of avulsion increases in the age range of $7-9$ years due to incomplete root development and minimal resistance of the alveolar bone/periodontal ligament (PDL) against extrusive forces during the eruption period of the teeth. The etiology of tooth avulsion varies in accordance with the type of dentition.In deciduous dentition avulsions are usually caused by hard objects hitting the teeth, whereas in permanent teeth avulsions are due to falls,fights,sportsinjuries, accidents and child abuse. ${ }^{2}$ In both the primary and permanent dentition ,maxillary central incisors are the teeth mostly avulsed. ${ }^{3}$ Incompetent lips and increased overjet are added predisposing factors for avulsion injuries. ${ }^{4}$ Tooth avulsion can lead to damage to pulp and periodontal ligament, which leads to post traumatic complications. Tooth avulsions may also cause injury to supporting tooth structure,lips and might lead to multiple avulsions. ${ }^{5}$ 
The standard protocol for treatment of an avulsed permanent tooth is to preserve and treat the supporting tissues and replant the avulsed tooth/teeth.Many factors delineate the success of a replanted tooth-extra-oral dry time,storagemedium,patients general health and maturity of root of the tooth. ${ }^{6}$ The period of extra-oral time and storage medium are the most critical components for the success of a replanted tooth. ${ }^{7}$ Here we discuss a case of delayed replantation of maxillary central incisors in a seven years old male child with root surface treatment with Silver Diammine Fluoride(SDF).

Case Report

A seven-years-old male child reported to the dental clinic with a chief complain of avulsed permanent teeth(Fig 1,2). The child had a trauma 15 hours back while playing with his friends in school. The child had visited a physician who administered tetanus toxoid and also put sutures for extra-oral laceration wound in mandible.There was no history of loss of consciousness or vomiting or any systemic disease. The parents had got the avulsed maxillary central incisors(11,21)in milk as storage media(Fig 3).The child being young we considered replantation of the teeth as the facial growth was not completed and both the child and parents were concerned regarding the esthetics of the child.The complete treatment plan was explained to the parents along with prognosis and written consent was taken. The parents were also explained about the poor prognosis of the teeth because of the increased extra-oral time. Intra-oral periapical radiograph did not reveal any broken fragments of alveolar bone or tooth(Fig 4). The sockets were cleaned with normal saline and Betadine(Win-Medicare Pvt.Ltd,NewDelhi,India) and the root surfaces were debrided too.This was a delayed replantation of more than 60 minutes,so it was decided to perform the endodontic therapy extraorally (Fig 5).Access was made,pulp was removed and canals irrigated with $5.25 \%$ sodium hypochlorite and $2 \%$ chlorhexidine.Biomechanical preparation was done till size F3 Protaper (Denstply Sirona,Canada)file.Tooth 11 was obturated with F3 Gutta Percha along with AH plus (Dentsply Sirona,Canada) after root end closure with amalgam whereas 21 was obturated with MTA(Dentsply Sirona,Canada). The canals were closed with Glass ionomer cement as interim restoration. The roots of both teeth were debribed and cleaned with pumice. The root of 11 was treated with Fluoride varnish(Fluoritop,ICPA Health,India) and 21 was treated with $\operatorname{SDF}$ (Fagamin,Tedequim,Argentina)(Fig 6,7). The sockets were curetted thourougly and blood clot was removed.Bleeding was controlled.The teeth 11 and 21 were placed inside the sockets gently with finger pressure after application of local anaesthesia(Fig 8). The teeth were splinted with soft orthodontic wires from first deciduos molar to first deciduous molar on both sides.i.e 54 to 64(Fig 9).Intra-oral periapical radiograph was taken to check the placement of replanted teeth in socket(Fig 10). The patient was prescribed antibiotics and analgesics for 7 days and sent with oral hygiene instructions. The patient was advised for soft diet for 7 days. The patient was recalled after 4 weeks for splint removal.Periapical radiograph was taken for checking the resorption, if any.During this period,the pandemic started(COVID-19)and the patient did not come up for follow up. We only monitored the case through video conferencing without any radiographs. After 26 months, with little decline in cases of COVID-19 and after much persuasion the parents agreed to come for follow up of the child.On clinical examination, 11 was showing pink discoloration on cervical region and OPG also confirmed resortion of root(Fig 11).21 was both clinically and radiographically sound.The case is being followed up still and the parents have been told about the prognosis of 11 .

\section{Discussion}

The complete displacement of tooth from its socket occurs when the tooth directly sustains a force.In both primary and permanent dentitions,maxillary central incisors are commonly avulsed because of their prominence in jaw. ${ }^{8}$ The guidelines of treatment of avulsed teeth may vary but the wide consensus is to replant the tooth as soon as possible.But sometimes it is not possible. The treatment depends on the root maturity of the avulsed tooth(Open /Closed apex) and the PDL cell viability. ${ }^{9}$ The PDL cells viability is dependent on the extra-oral time and the storage medium. The extra-oral time defines the prognosis of the replanted teeth.Clinical studies have elaborated that the prognosis is best for replantation of teeth within 5 minutes. The extra-oral time of more than 60 minutes will lead to loss of PDL cell viability. ${ }^{10}$ The storage and transport medium during the extra-oral time also serves to decide the prognosis.In those patients with more extra-oral time of avulsed tooth the,tooth should be stored in suitable medium like HBSS solution,milk,saliva 
,coconut water and if nothing available then water till he/she gets to a dentist. ${ }^{11}$ There have been reports of replanted teeth remaining in function for over 30 years. On an average, they are functional at least for 5 years and most are ultimately lost because of progressive root resorption or other associated problems like ankylosis. ${ }^{12}$

In the presented case,the extar-oral time was more than 15 hours but teeth were bought in milk as storage medium.The replantation was done in accordance to International Association of Dental Traumatology( IADT )guidelines. ${ }^{13}$ The extra-oral time was more than 60 minutes,so the endodontic treatment was done extra-oral prior to replantation. As the PDL cells and the pulp will not be viable,revascularisation can not be attempted.The long term prognosis of teeth with delayed replantation is poor,because of non viability of PDL cells.Most of the avulsion injuries occur before the facial growth is completed. ${ }^{14}$ Ideal requisite is to prevent the resorption of bone till facial growth is completed.Replantation also prevents the psychological trauma associated with the facial appearance and esthetics. The facial esthetics was the major concern of the parents and the child in our case. The replantation is to be done till the child can be ready for a more permanent treatment option like fixed prosthesis or implant.If replantation can not be done we can manage the case with orthodontic space closure,auto transplantation of another tooth. ${ }^{15}$ The avulsed tooth should be stored in storage media until replanted. Further, conditioning the root surface of the tooth with the appropriate agent can increase the chances of functional healing. PDL vitality is the primary factor in the prevention of ankylosis in cases of dental avulsion. A variety of adjunctive treatments have been proposed to prevent and delay root resorption before replantation thereby increasing the survival of replanted teeth.Various materials like sodium fluoride,triple antibiotic paste,Enamel Matrix Derivative(EMD),Fibroblast growth Factor(FGF) have been used for root surface treatment. ${ }^{16,17,18,19}$ But till now not a single case report has attempted SDF for root surfcae treatment.We utilised SDF and have got good results till 26 months.More cases have to be done to come to a conclusion on the role of SDF as surface treatment agent for root in avulsed teeth.

\section{Conclusion}

Replantation of avulsed tooth has to be done even in case of prolonged extra-oral time. The parents have to be explained about the prognosis.In young patients in whom the growth has not ceased the replanted teeth will help to prevent bone resorption and also prevent the psychological impact on the child.Here we discussed the use of SDF for root treatment which is probably the first time followed for 26 months without resorption. Although it might be early to judge the success,still SDF can be tried in avulsed tooth for root treatment.

Why this paper is important to paediatric dentists

- Surface treatment of root is essential for any delayed replantation case.Many products have been used but this is the first case to utilise SDF and got good results

- The pediatric dentists must try to replant the avulsed teeth as soon as possible which if not possible can be delayed and replanted

- Use of storage media is important when transporting the avulsed teeth.

Conflict of interest-Nil

The Author has done the case,searched the databases and written the manuscript.

\section{References}

1. American Academy of Pediatric Dentistry. Guidelines on management of acute dental trauma. Pediatr Dent 2011;34:12-3

2. Ram D, Cohenca N. Therapeutic protocols for avulsed permanent teeth: Review and clinical update. Pediatr Dent 2004;26:251-5.

3. Fidel SR, Santiago MR, Reis C, Pinho MA, Fide RA. Successful treatment of a multiple dental trauma: Case report of combined avulsion and intrusion. Braz J Dent Traumatol 2009;1:32-7

4. Flores MT, Andersson L, Andreasen JO, Bakland LK, Malmgren B, Barnett F, et al. Guidelines for the management of traumatic dental injuries. II. Avulsion of permanent teeth. Dent Traumatol 
2007;23:130-6

5. Mc Tigre DJ. Diagnosis and management of dental injuries in children. Dent Clin North Am 2000;47:1067-84

6. Savas S, Kucukyilmaz E, Akcay M, Koseoglu S. Delayed replantation of avulsed teeth: Two case reports. Case Reports in Dentistry. 2015;28 (2):88-96.

7. Al-Obaida M. Knowledge and management of traumatic dental injuries in a group of Saudi primary schools teachers. Dent Traumatol. 2010;26 (4):338-41

8. Andersson L, Andreasen J, Day P, Heithersay G, Trope M, DiAngelis A, et al. Guidelines for the management of traumatic dental injuries: 1. Fractures and luxations of permanent teeth. Pediatr Dent. 2017;39 (6):412-9.

9. Donaldson M, Kinirons MJ. Factors affecting the time of onset of resorption in avulsed and replanted incisor teeth in children. Dent Traumatol. 2001;17 (5):205-9

10. McIntyre J, JY JL, M MT, Jr JWV. Permanent tooth replantation following avulsion: Using a decision tree to achieve the best outcome. Pediatr Dent. 2009;31 (2):137-44

11. Khalilak Z, Shikholislami M, Mohajeri L. Delayed tooth replantation after traumatic avulsion: A case report. Iran Endod J. 2008;3 (3):86-9

12. Martins W, Westphalen V, Westphalen F. Tooth replantation after traumatic avulsion: a 27-year follow up. Dent Traumatol. 2013;20 (2):101-5.

13. Fouad AF, Abbott PV, Tsilingaridis G, Cohenca N, Lauridsen E, Bourguignon C, O'Connell A, Flores MT, Day PF, Hicks L, Andreasen JO, Cehreli ZC, Harlamb S, Kahler B, Oginni A, Semper M, Levin L. International Association of Dental Traumatology guidelines for the management of traumatic dental injuries: 2. Avulsion of permanent teeth. Dent Traumatol. 2020 Aug;36(4):331-342.

14. Andreasen JO. Traumatic dental injuries: A manual Copenhagen. Munksgaend: 1999. p. 349

15. Kim SG, Ryu SI. Enamel matrix derivative for replanted teeth in animal models a systematic review and meta-analysis. Restor Dent Endod. 2013;38(4): 194-203.

16. Gulinelli JL, Panzarini SR, Fattah CM , et al. Effect of root surface treatment with propolis and fluoride in delayed tooth replantation in rats. Dent Traumatol. 2008;24(6): 651-7

17. Heiji L, Heden G, Svardstrom G, Ostgren A. Enamel matrix derivative (Emdogain) in the treatment of intrabony periodontal defects. J Clin Periodontol. 1997;24: 705-14

18. Rifkin DB, Moscatelli D. Recent developments in the cell biology of basic fibroblast growth factor. J Cell Biol. 1989;109: 1-6

19. Panzarini SR, Gulinelli JL, Poi WR, Sonoda CK, Pedrini D, Brandini DA. Treatment of root surface in delayed tooth re-plantation a review of literature. Dent Traumatol. 2008;24(3): 277-8

\section{Hosted file}

First page.docx available at https://authorea.com/users/457048/articles/553918-delayedreplantation-of-an-avulsed-permanent-tooth-in-a-young-patient-does-silver-diamminefluoride-surface-treatment-has-a-role 

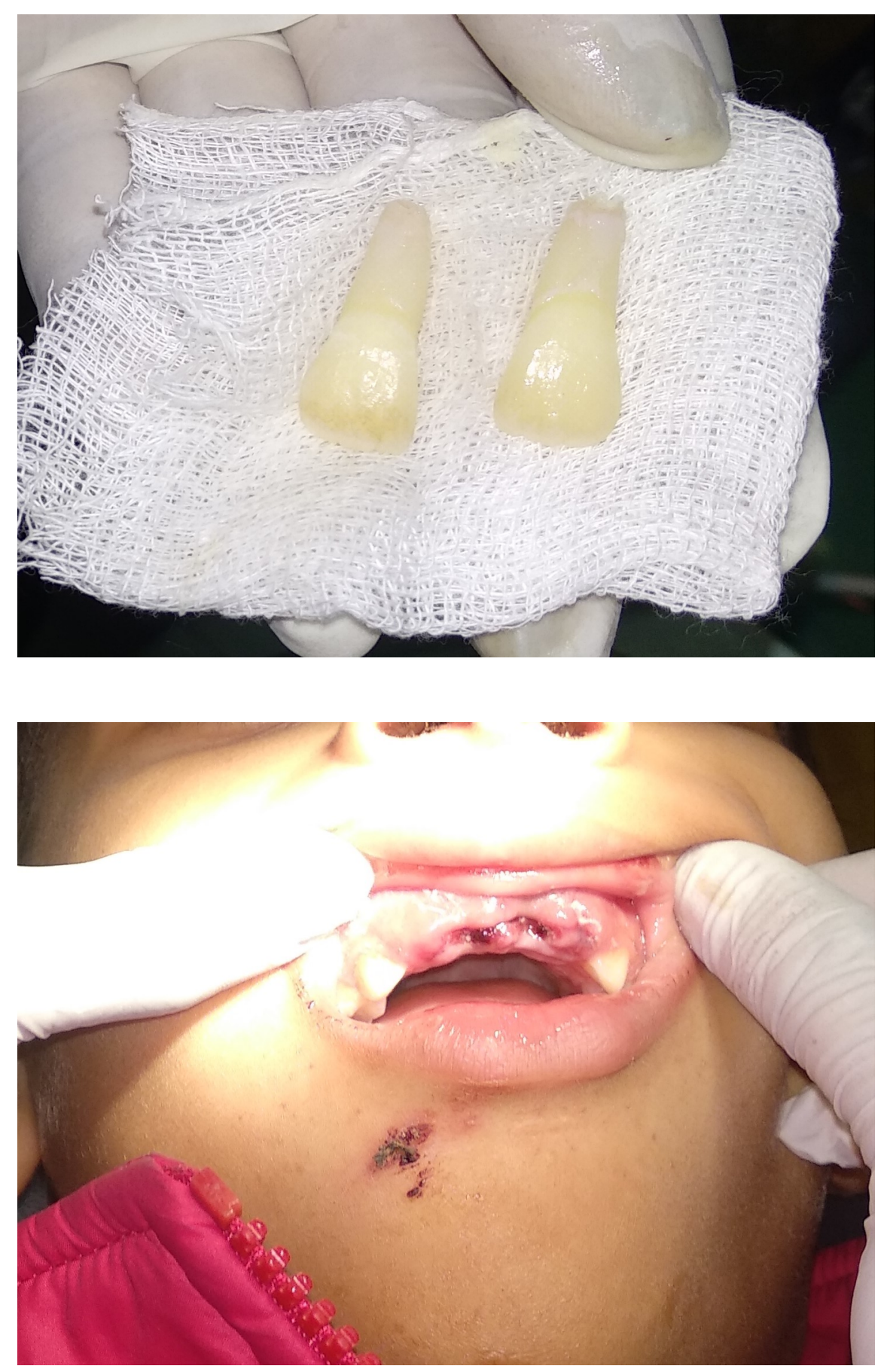


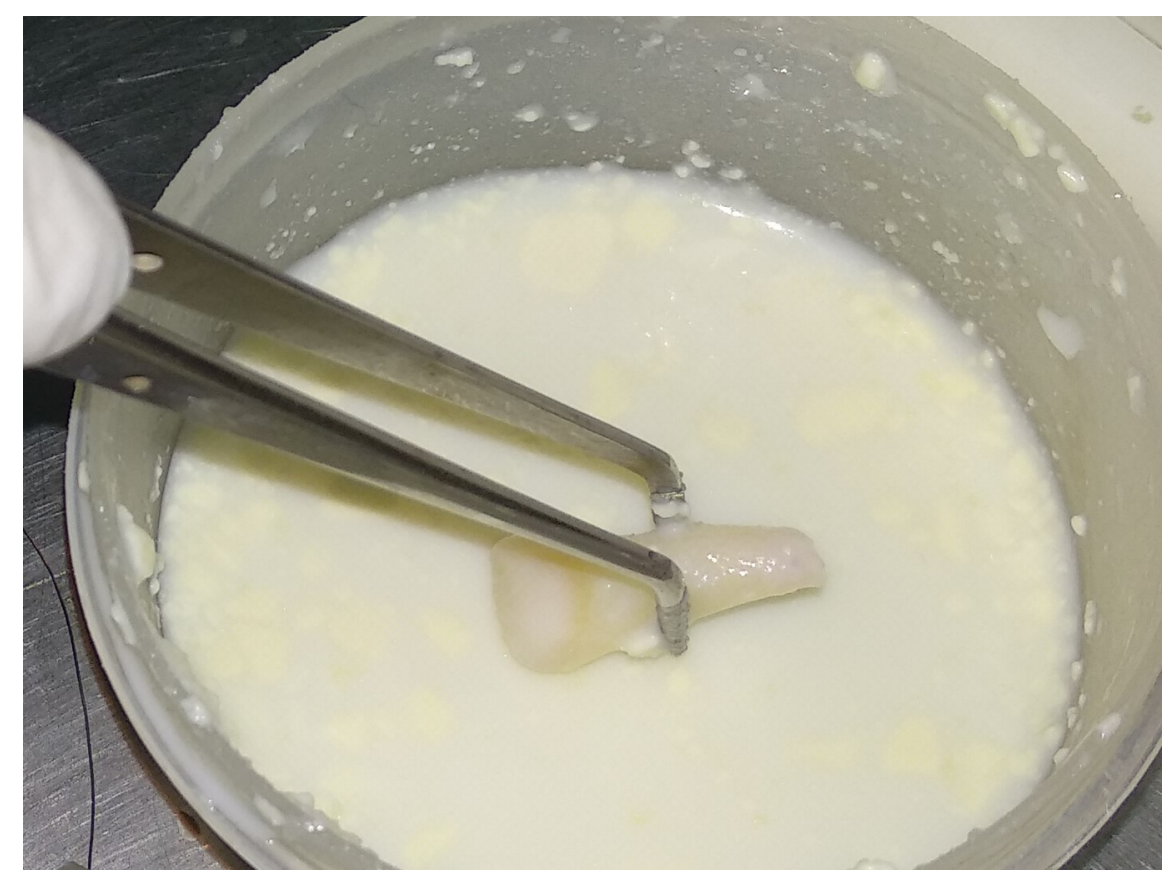




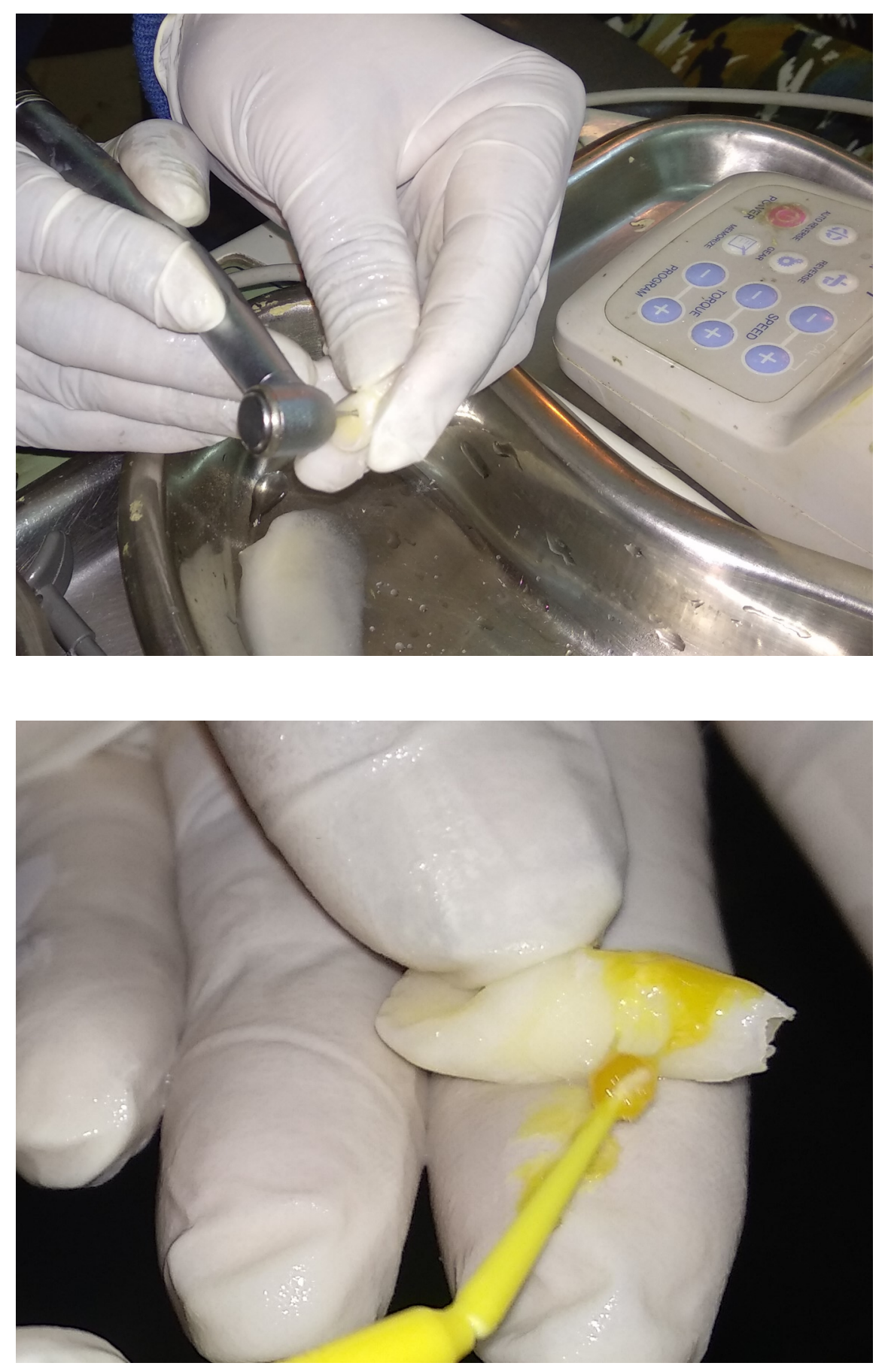


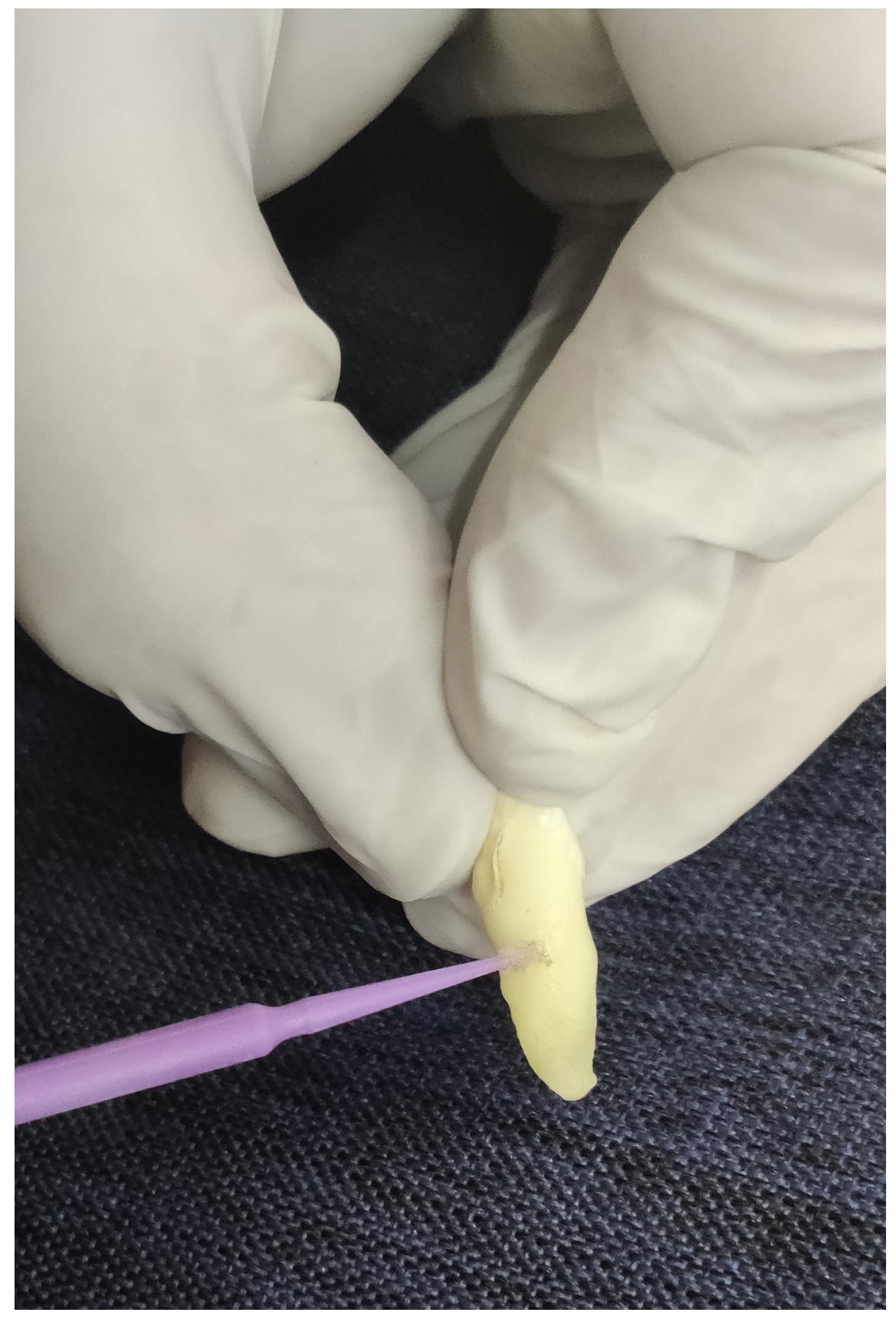



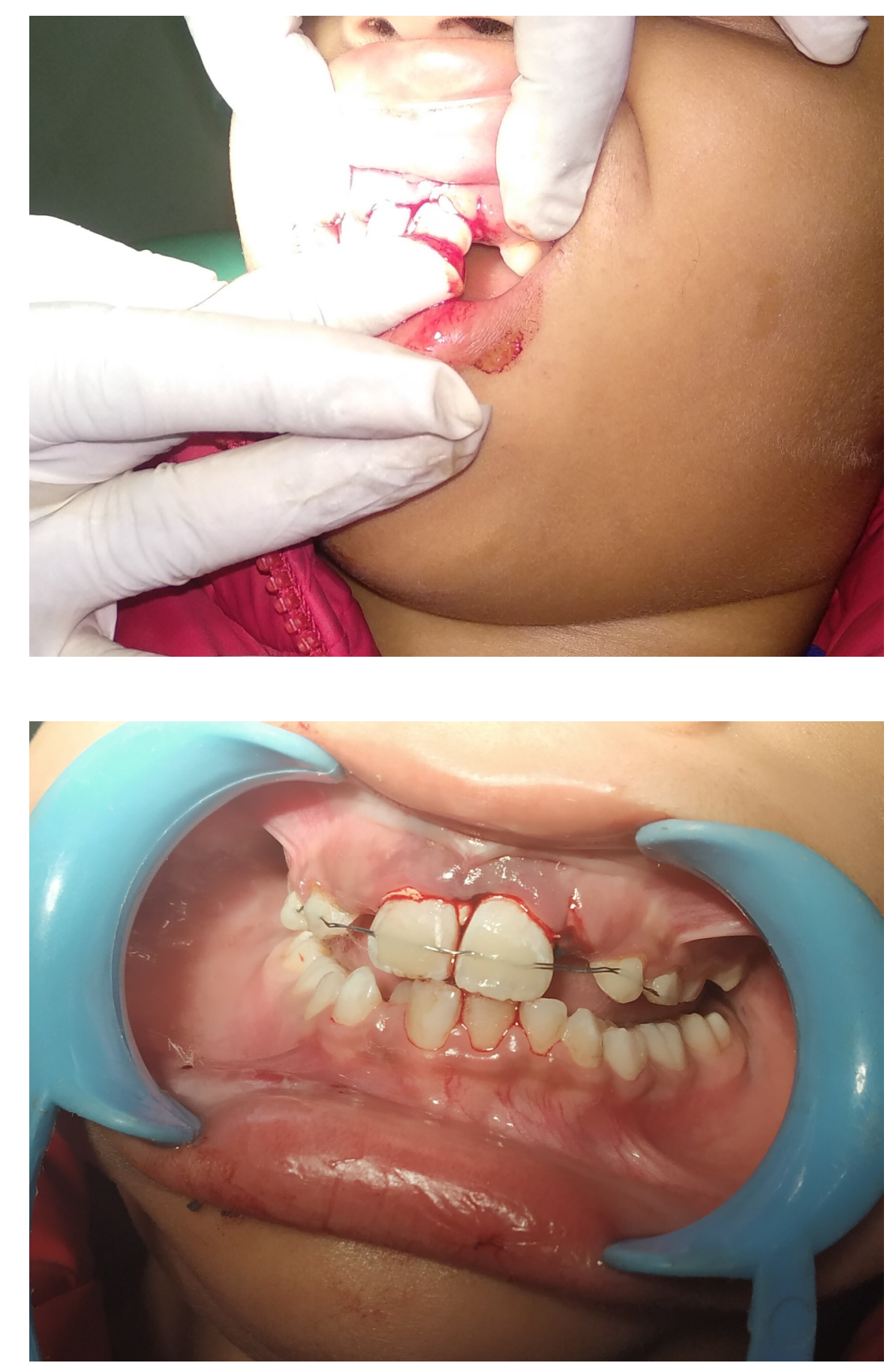


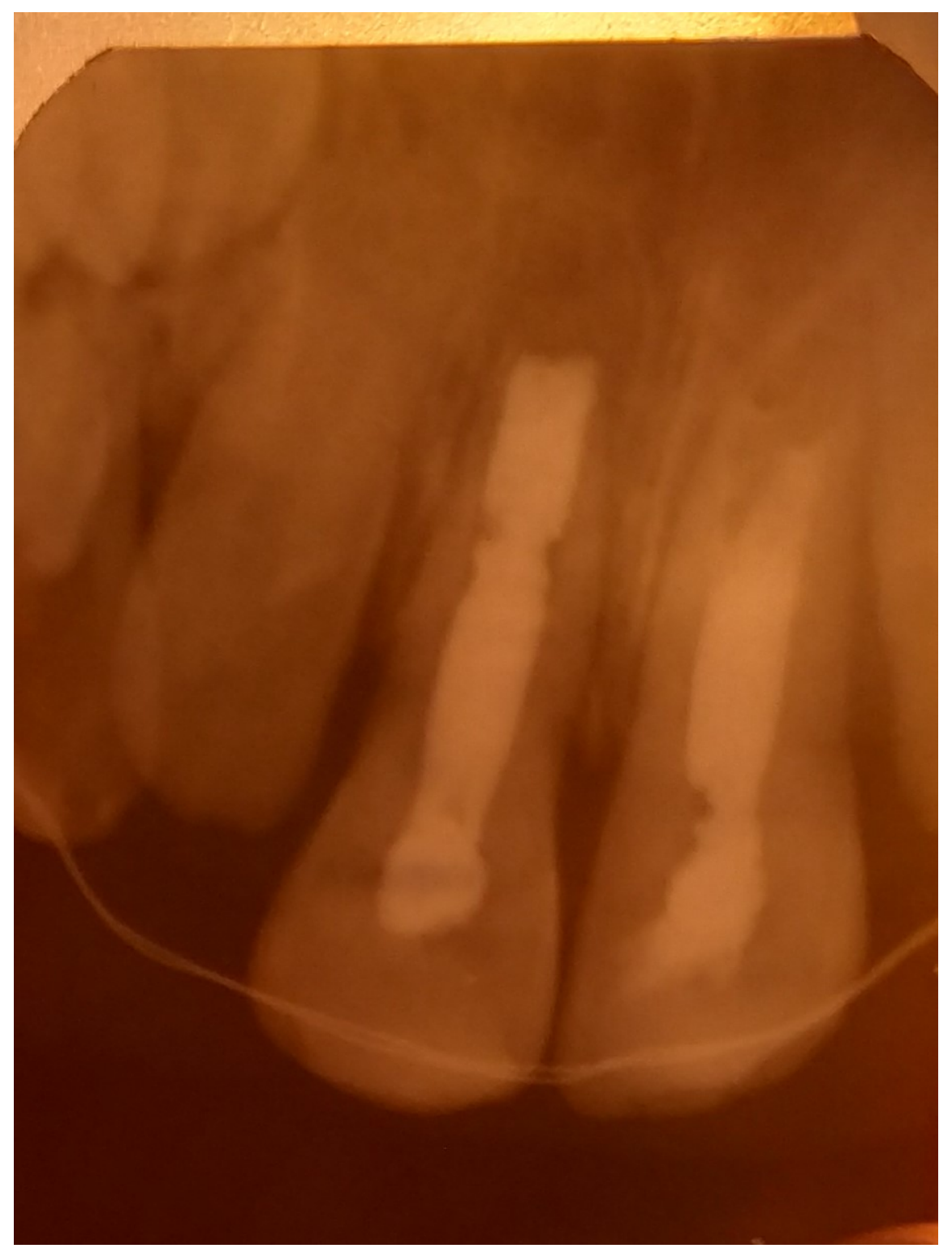




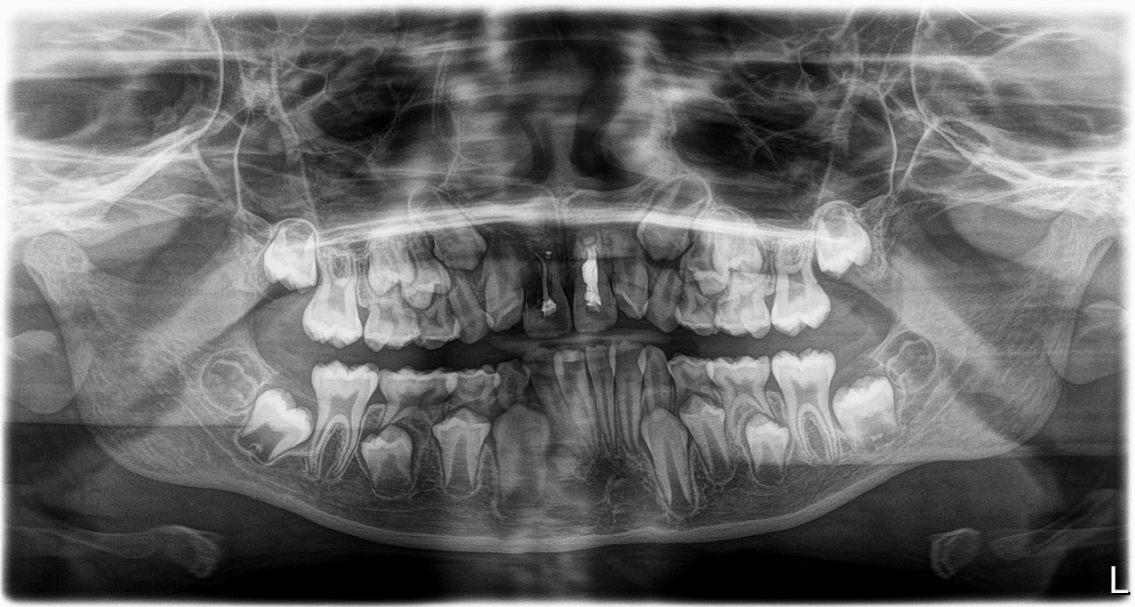

